Resumo

\title{
A prática do Rugby em Cadeira de Rodas como fator de melhora da capacidade de recuperação cardiopulmonar após esforço em atletas da modalidade
}

Alexssander de Souza Mello Bsci, Miriam Raquel Mainenti PhD

Introdução: O Rugby em Cadeira de Rodas (RCR) foi desenvolvido para que pessoas com comprometimento nos quatro membros (tetraplegia ou tetraequivalência) pudessem praticar um esporte coletivo em cadeira de rodas. Devido às características cardiopulmonares associadas às lesões, é fundamental que o treinador tenha conhecimento das capacidades e limitações dos atletas, para otimizar o treinamento e o rendimento.

Objetivo: Verificar a recuperação da capacidade cardiopulmonar após esforço de atletas de RCR.

Métodos: Um estudo seccional com 22 atletas realizando um teste de esforço cardiopulmonar até a intensidade máxima suportada, analisando as variáveis consumo oxigênio $\left(\mathrm{VO}_{2}\right.$ ) e Ventilação pulmonar (VE) no pico do esforço e a cada minuto de recuperação $\left(1^{\circ}\right.$, 2으, e $\left.3^{\circ}\right)$. 0 teste seguiu um protocolo de rampa em um cicloergômetro com carga inicial de $20 \mathrm{~W}$ e implementos de $2 \mathrm{~W}$ ou $5 \mathrm{~W}$ de acordo com a Classificação Funcional (CF) do atleta, permanecendo no mesmo após a interrupção realizando uma recuperação ativa controlada. Comparou-se os valores obtidos entre as duas equipes com o teste $\mathrm{T}$ de Student e feita uma análise de correlação de Pearson com a recuperação cardiopulmonar e a CF dos atletas.

Resultados: $\mathrm{O}$ Grupo de Alto Rendimento possui uma maior recuperação do $\mathrm{VO}_{2}$ $(\mathrm{ml} / \mathrm{kg} / \mathrm{min})$ nos três minutos subsequentes ao esforço com média de 38,59 $( \pm 13,62, \quad p=0,095) ; \quad 47,68 \quad( \pm 14,18, \quad p=0,255)$ e $57,10 \quad( \pm 13,07, \quad p=, 080)$ respectivamente, bem como uma maior recuperação da VE (L/min) no segundo $34,21( \pm 13,42, \mathrm{p}=0,040)$ e terceiro $50,20( \pm 15,12, \mathrm{p}=0,026)$ minutos quando comparado ao Grupo de Atletas Profissionais - $\mathrm{VO}_{2}$ : 20,23 ( $\left.\pm 36,82\right) ; 38,83$ $( \pm 19,87)$ e $45,21( \pm 14,54)$ - VE: $20,03( \pm 13,54)$ e $34,18( \pm 9,14)$ para os mesmos tempos subsequentes. Tempo de lesão e CF foram similares entre os grupos.

Conclusão: Maior volume de prática do RCR tende a propiciar melhor capacidade de recuperação cardiopulmonar para essa população. 